\title{
Alkali-silica reaction and microstructure of concrete subjected to combined chemical and physical exposure conditions
}

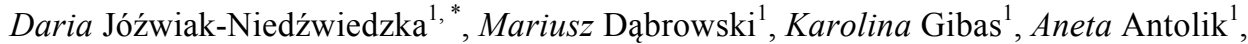 \\ and Michat $A$. Glinicki ${ }^{1}$ \\ ${ }^{1}$ Institute of Fundamental Technological Research, Polish Academy of Sciences, Pawińskiego 5b, 02- \\ 106 Warsaw, Poland
}

\begin{abstract}
Salt solutions are used to ensure safe driving conditions during winter. $\mathrm{NaCl}$ deicer is the most often used brine in Polish climatic zone. The chemical effects of this type of chloride-based deicer in wetting and drying (WD) and temperature cycles on concrete need to be better understood. This research was focus to study the microstructure of air-entrained pavement concrete after combined chemical $(10 \%$ of $\mathrm{NaCl})$ and physical (WD and $60^{\circ} \mathrm{C}$ ) exposure conditions. The adopted WD and temperature regime was designed to verify the hypothesis that regularly alternating wetting and drying cycles with external alkali supply from deicer salt will provoke the Alkali-Silica Reaction (ASR). The aggregates varied their origin and mineralogical composition. The microscopic examination was carried out on concrete specimens using SEM with EDX. The microscopic analysis has shown that main reason for concrete deterioration during cyclic chemical and physical exposure conditions was both physical influence - WD cycles and the chemical influence - ASR (primarily, the fine aggregate which lead to form of alkali-silica gel). The expansive gel was shown to be capable of destroying the test specimens. Also differences in mineralogical composition of coarse aggregates influenced on the concrete prism expansion due to ASR.
\end{abstract}

\section{Introduction}

In central, eastern and northern Europe, and in the north America the climatic conditions in the autumn and winter season are particularly severe for concrete construction and concrete infrastructure. The successive wetting/drying (WD) and freezing/thawing (FT) cycles cause both external and internal concrete deterioration. In a winter season, the outdoor structures may (in certain cases) be exposed to over 100 cycles. The exposure conditions become even more severe in the urban and suburban areas located in cold regions as a result of heavy use of deicing salts. The safe driving conditions during winter months are of primary concern, hence large quantities of deicing chemicals are applied in order to clear the pavement and to allow for the normal traffic flow, [1]. Highway deicers often contain chlorides as freezing-

\footnotetext{
*Corresponding author: djozwiak@ippt.pan.pl
} 
point depressants because of their cost-effectiveness. The sodium chloride $(\mathrm{NaCl})$ is the most frequently used deicer, [2]. Chloride-based deicers may have detrimental effects on concrete infrastructure - which is often manifested by expansion, mass change, reduction of the dynamic modulus of elasticity, [3] and, most of all, strength, [4]. Generally, the results of several past studies $[2,3,5-7]$ on the effects of deicers on concrete vary greatly, depending on such factors as the exposure conditions, concentrations of the deicers, and the test temperature.

Previous research studies have shown that both $\mathrm{MgCl}_{2}$ and $\mathrm{CaCl}_{2}$ deicers are known to accelerate the alkali-carbonate reaction in concrete containing reactive dolomite aggregates $[8,9]$. Rajabipour et al. [10] prepared a list of known and still not fully understood phenomena related to the ASR. They stated, among others, that the ingress of $\mathrm{NaCl}$ into concrete, as a deicing salt, has been thought to exacerbate certain cases and laboratory studies of ASR, while having no effect on expansion in others.

For the performance testing of concrete in respect to ASR risk two methods were developed in Germany $[11,12]$. Both methods comprise of cyclic exposure of concrete specimens to wetting-drying-soaking in $\mathrm{NaCl}$ solution while the changing the temperature withing the range from -20 to $60^{\circ} \mathrm{C}$ and from +20 to $60^{\circ} \mathrm{C}$, respectively. The VDZ method [Muller] has been implenented at IPPT PAN for the ASR risk evaluation of domestic aggregates in concrete.

In this study the most frequently applied deicing solution - $\mathrm{NaCl}$ was used to evaluate the physico-chemical alterations in air-entrained pavement concretes. To assess the effect of salt on concrete microstructure, a high concentration of $\mathrm{NaCl}$ was assumed $-10 \%$. The concretes were subjected to wetting/drying, which were designed to be reasonably realistic with respect to the actual field exposure conditions, and temperature up to $60^{\circ} \mathrm{C}$ was applied. The adopted $\mathrm{WD}$ and temperature regime was designed to verify the hypothesis that regularly alternating wetting and drying cycles with external alkali supply from deicer salt will provoke the AlkaliSilica Reaction (ASR). The microscopic examination was carried out to analyze the causes for this kind of behaviour. The microstructure of concretes specimens exposed to varied conditions was observed using Scanning Electron Microscope (SEM) with Energy Dispersive X-Ray Analysis (EDX).

\section{Experimental program}

\subsection{Materials and mixture proportions}

Portland cement CEM I $42.5 \mathrm{R}\left(\mathrm{Na}_{2} \mathrm{O}_{\mathrm{eq}}=0.6 \%\right)$, natural siliceous sand with a maximum grain size of $2 \mathrm{~mm}$ (specific gravity $2.65 \mathrm{~g} / \mathrm{cm}^{3}$ ), tap water, a superplasticizer based on a modified policarboxylanes and air entraining admixture were used for concrete manufacturing. Six different coarse aggregates were used: amphibolite (A), basalt (B), granite (G), dolomite (D), limestone (L), and crushed from glacial deposit (Gr). The petrographic analysis of the above aggregates is presented in $[13,14]$. Concrete mixes were designed with constant cement content $\left(360 \mathrm{~kg} / \mathrm{m}^{3}\right)$, constant water to cement ratio of 0.45 , a constant slump of $100 \div 180$ $\mathrm{mm}$ and the air content from $5.5 \%$ to $7.5 \%$ in the fresh mix. To achieve the target slump and air content the required amount of chemical admixtures was established experimentally.

Prismatic $75 \times 75 \times 285 \mathrm{~mm}$ specimens after casting, were protected from moisture loss and stored in the moulds at $20 \pm 2^{\circ} \mathrm{C}$ for 1 day. Then the prisms were demoulded and stored in a water for 27 days (temp. $20^{\circ} \mathrm{C}$ ). After the 27 days of pre-conditioning, the prisms were subjected to 10 fourteen-day cycles: 5 days in $60^{\circ} \mathrm{C}, 2$ days $20^{\circ} \mathrm{C}$ and $10 \%$ of $\mathrm{NaCl}$ solution, 6 days in $60^{\circ} \mathrm{C}$ and a minimum $98 \%$ R.H., 1 day $20^{\circ} \mathrm{C}$ and $98 \%$ R.H. The physical changes 
taking place in the prismatic specimens were monitored which included biweekly measurements of resonant frequencies, mass and length changes.

\subsection{Test methods}

The microstructural analysis was performed on the $25 \times 42 \times 10 \mathrm{~mm}$ specimens cut from the prisms after 10 cycles of alternating storage. Schematic illustration of the specimen prepared for the test and longitudinal section of beam with approximate location of SEM specimens is presented in Fig. 1. The small specimens from the beams were cut from their edges and from the middle. Above selected localization of the specimens was chosen as the most $(\mathrm{Z})$ and least (S) influenced by $\mathrm{NaCl}$ deicer.
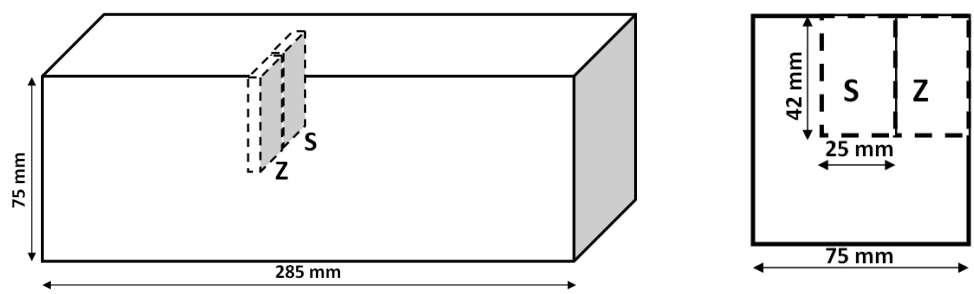

Fig. 1. Schematic of prismatic specimen used for experiment and the fragment of transverse section of the specimen showing approximate location of specimens for microstructural analysis.

After completion of exposure period, the specimens for microstructural investigation were obtained by slicing these specimens with a slow speed diamond saw. The samples were then dried in an oven at $50^{\circ} \mathrm{C}$ for 3 days, vacuum-impregnated with a low-viscosity epoxy, lapped and polished using a special procedure for SEM specimens. Each specimen was prepared in such a way that the polished face which was to be examined was a cut surface and two of the edges of this face of interest were originally exposed to the deicer (localization Z) or one edge (localization S).

A strip of conductive tape was then attached to each polished sample, after which they were coated with a thin layer of carbon for about a minute. Each of the specimen was thoroughly examined using JEOL JSM-6380 LA SEM-EDX in the backscatter mode using an acceleration voltage of $15 \mathrm{kV}$.

\section{Results and discussion}

\subsection{Visual inspection}

The visual inspection revealed that almost all concrete specimens showed the crack network on the surface, also the single pop-out or the beginning of the surface scaling of the edges were observed for specimens with aggregate from glacial deposits (Gr), Fig. 1. It was also stated that concrete specimens with basalt aggregate (B) did not undergo any visible distress during the period of 140 days subjected to physical and chemical exposure conditions. 
a)

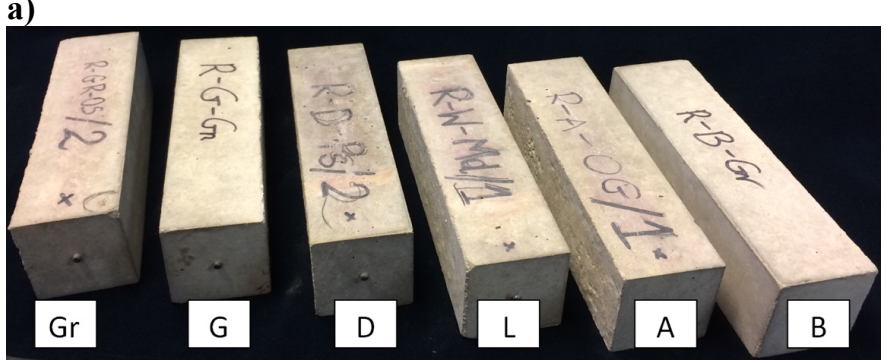

b)

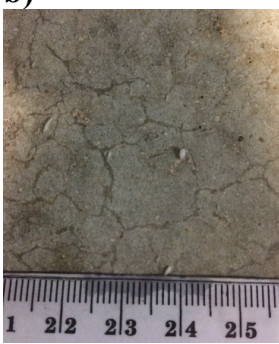

Fig. 2. Specimens subjected to 10 cycles of WD conditions, $10 \%$ of $\mathrm{NaCl}$ and $60^{\circ} \mathrm{C}$ : a) general view one beam from each concrete, prismatic specimens $75 \times 75 \times 285 \mathrm{~mm}, \mathrm{~b}$ ) surface view - with granite aggregate $(\mathrm{G})$.

\subsection{SEM analysis}

When subjected to WD and temperature cycles and exposed to $10 \%$ of $\mathrm{NaCl}$ solution the concrete specimens with amphibolite aggregate $(A)$, granite $(\mathrm{G})$ and aggregate from glacial deposits (Gr) suffered more extensive surface deterioration than other concrete specimens. The cracks which were localized in the upper part of the analyzed specimen were mostly parallel to the surface and were empty. The lower part of the analyzed specimens, $\sim 40 \mathrm{~mm}$ from the top, did not showed any spectacular cracking, Fig. 3.

a)

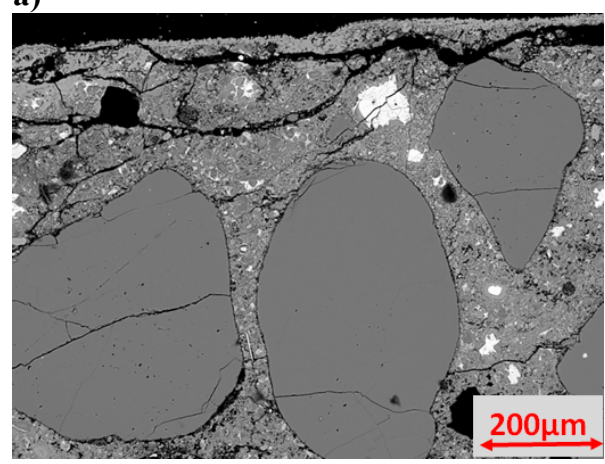

b)

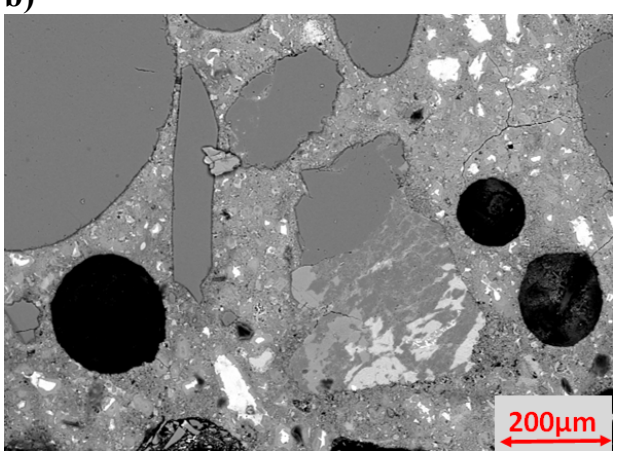

Fig. 3. Scanning electron micrograph for the a) top surface (up to $0.6 \mathrm{~mm}$ ), and b) lower part, $40 \mathrm{~mm}$ of concretes with amphibolite aggregate (A); specimens localisation - internal (S), scale bar $=200 \mu \mathrm{m}$.

In all tested specimens changes in the matrix due to severe exposure conditions were visible. The cracks in the matrix were present in all analyzed concrete specimens, regardless of whether it was an external (Z) or an internal (S) specimen. The most severe matrix degradation has been observed in concrete with glacial deposit aggregate (Gr). Figure 4 shows the macro and micro cracking in concrete made with $(\mathrm{Gr})$ aggregate. Cracks were present in the matrix and the debonding of aggregate was visible in all the concrete specimens, but the most extensive debonding was present in cover zone. 
a)

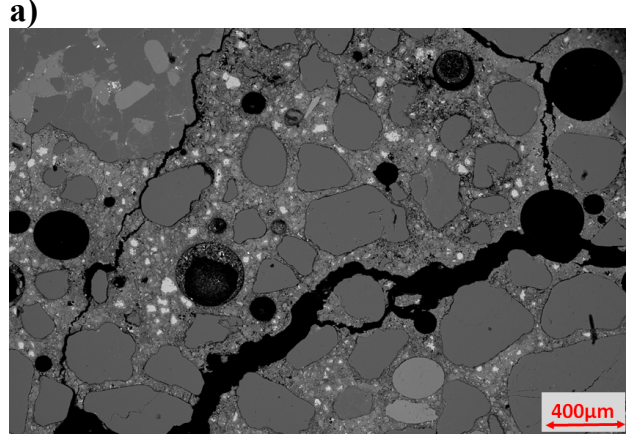

b)

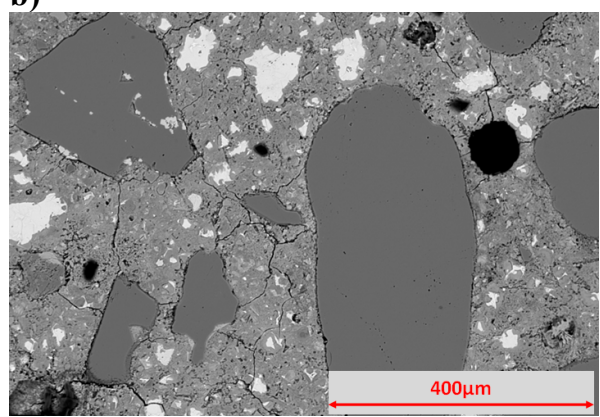

Fig. 4. Scanning electron micrograph of the cracked concrete with glacial deposit aggregate (Gr), a) larger cracks, b) smaller cracks, scale bar $=400 \mu \mathrm{m}$; specimens localisation - internal (S).

In both kinds of analyzed specimens, from the edge of the beams $(Z)$ and from the middle of the beams (S), the ettringite and Friedel's salt were present in the cover zone, Fig. 5. Ettringite needles were totally or partially filling the air-voids and Friedel's salt was localized in the cement matrix.
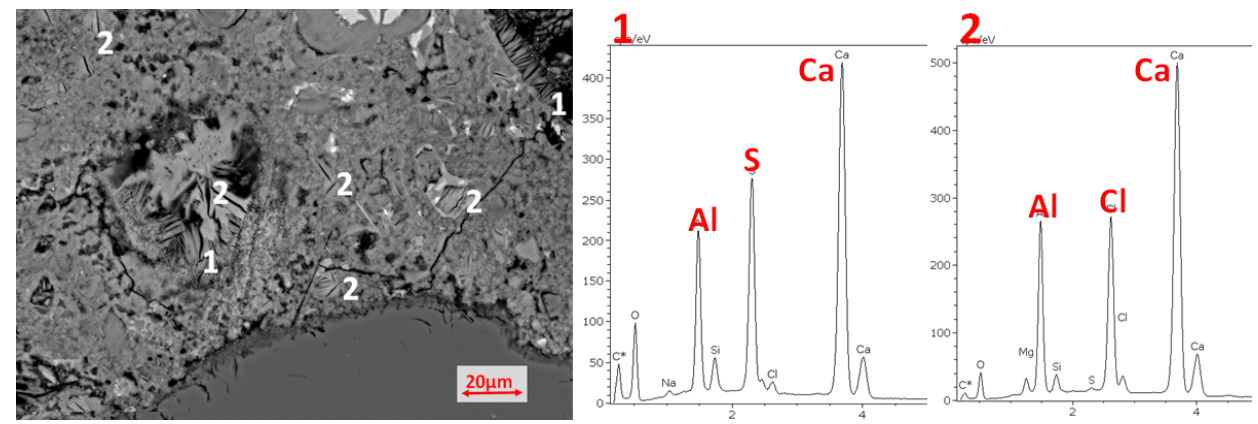

Fig. 5. Scanning electron micrograph of the cement matrix with visible a) ettringite deposit (1), b) Friedel's salt (2); concrete with glacial deposit aggregate (Gr), scale bar $=20 \mu \mathrm{m}$; specimens localisation - external (Z).

Chloride penetration profiles for concrete specimens in $10 \%$ of $\mathrm{NaCl}$ solution were comparable for all tested specimens. The microstructural changes for all concretes were observed in terms of formation of Friedel's salt in the top and bottom $(\sim 40 \mathrm{~mm}$, from the surface) regions of the specimens exposed to $\mathrm{NaCl}$ salt. The lowest deposition of Friedel's salt has been observed in concrete specimens which were taken from the middle of the tested beams. Additionally Friedel's salt was present only in a cement matrix, the air-voids contain only a slight signs of this product. The salt was homogenously distributed in all cement matrix in cover zone. Fig. 6 presents an example of mapping of aluminium and chloride content in concrete with amphibolite aggregate (A). The brighter dots of $\mathrm{Al}$ and $\mathrm{Cl}$ are overlapping, which corresponds to Friedel's salt. 
a)

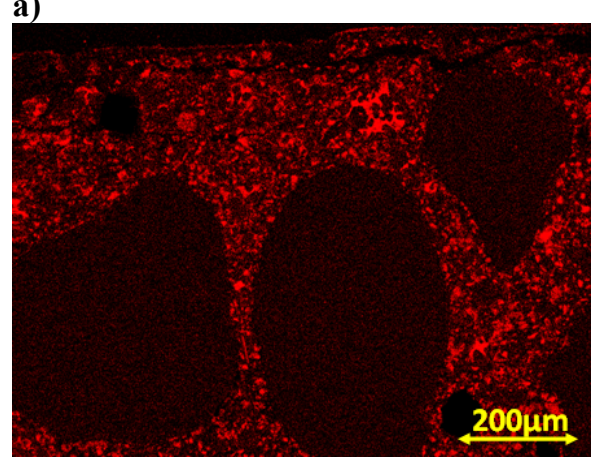

b)

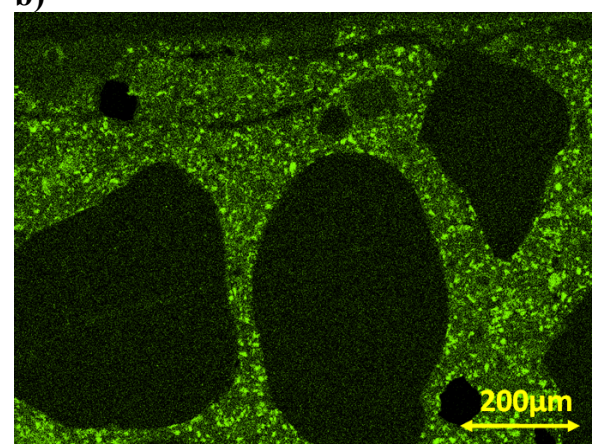

Fig. 6. Mapping taken on the top surface (up to $0.6 \mathrm{~mm}$ ) of concretes with amphibolite aggregate (A): a) aluminium content, b) chloride content; specimens localisation - internal (S), scale bar=200 $\mu \mathrm{m}$.

When the symptoms of ASR were visible in the analyzed specimens, they occurred in places that were furthest from the outer edges of the beams. The greatest occurrence of the alkali-silica gel was in the bottom of the specimens labeled (S). The analyzed specimens differed in vulnerability to ASR occurrence, depending of the origin of coarse aggregate. The most severe degradation caused by ASR was visible in concrete with aggregate from glacial deposit (Gr), amphibolite (A) and with granite aggregate $(\mathrm{G})$. The alkali-silica gel was filling cracks and air-voids in tested concrete. Due to the considerable variety of rock and mineral types which were found in the analysed crushed gravel from glacial deposits 13, the highest potential to ASR occurrence was expected. The example of the $\mathrm{Si}-\mathrm{Ca}-\mathrm{Na}-\mathrm{K}$ gel in concrete with (Gr) aggregate is showed in the Fig. 7. In this particular example the sandstone with silica (chalcedonite) cementation was responsible for the ASR phenomenon.
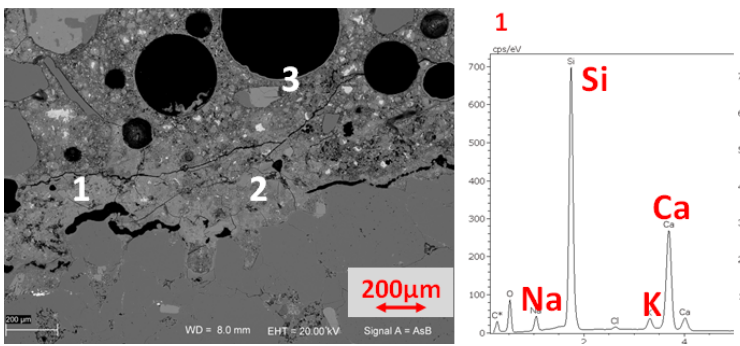

2

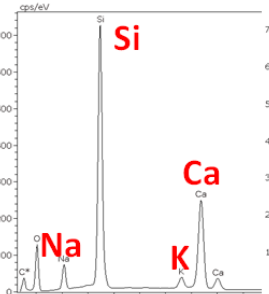

3

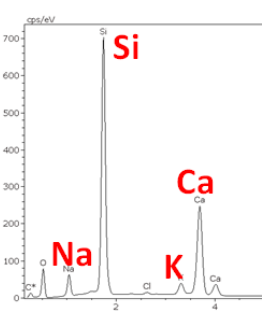

Fig. 7. Scanning electron micrograph of the cracked concrete with glacial deposit aggregate (Gr), the $\mathrm{Si}-\mathrm{Ca}-\mathrm{Na}-\mathrm{K}$ gel is shown; scale bar $=200 \mu \mathrm{m}$; specimens localisation - internal (S).
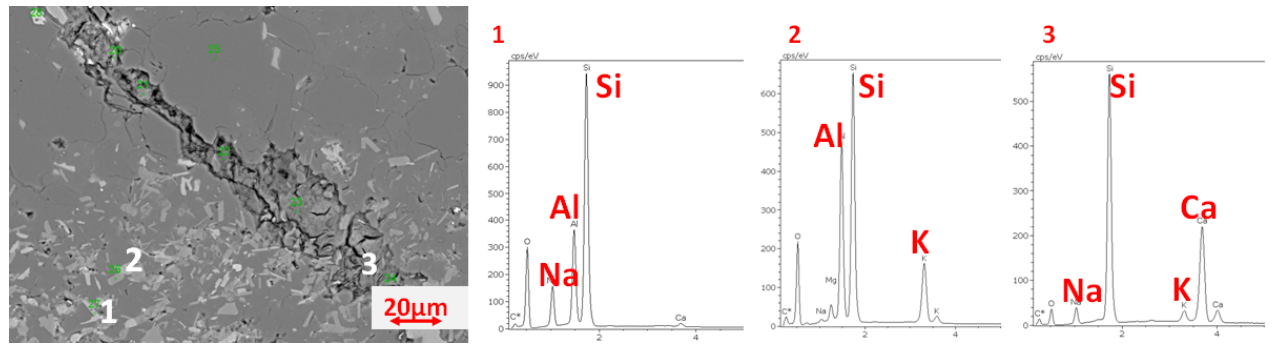

Fig. 8. Scanning electron micrograph of the cracked concrete with amphibolite aggregate (A); 1- albite, 2-K-feldspar, 3-the Si-Ca-Na-K gel; scale bar=200 $\mu \mathrm{m}$; specimens localisation - internal (S). 
Concretes with amphibolite and granite aggregate showed also significant signs of ASR. The SEM-EDX analysis revealed that the cracks in above aggregates were filled by Si-CaK-Na gel, Fig. 8. Minerals like K-feldspar and albite were found in coarse aggregate, and they suggest to provoke ASR. The cracks in an aggregates started in the center of grains and the sodium from deicer would start the reaction at the grain boundary, like in Fig. 10.

In coarse aggregate, dolomite (D) and limestone (L), and in siliceous sand visible signs of ASR were present - Si-Ca-Na gel in cracks, Figs. 9, 10. In the Fig. 9 the fibrous crystals are visible beneath dolomite grain. They are filling the main crack, which propagates through whole grain. Fig. 10 presents a cracked sand particle with visible ASR gel, which comes through the sand grain into the air-void from one side, and into the cement matrix from other side.

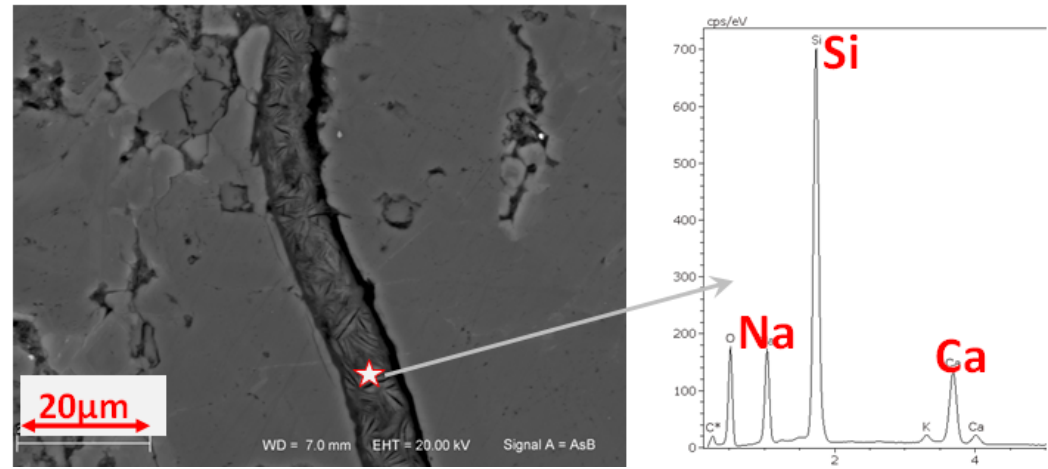

Fig. 9. Scanning electron micrograph of the cracked dolomite grain (D), the Si-Ca-Na gel is shown; scale bar $=200 \mu \mathrm{m}$; specimens localisation - internal (S).

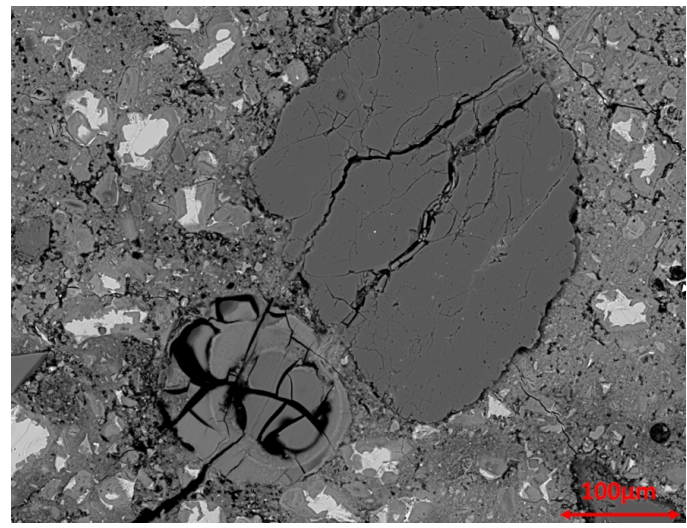

Fig. 10. Scanning electron micrograph of the sand grain with alkali-silica gel in cracks and in the airvoid, scale bar $=100 \mu \mathrm{m}$.

\section{Discussion}

The observed damage due to ASR was various depending on the type of aggregate. The alkali-silica gel passed through whole grains of siliceous sand and then into the cracks and air-voids, Fig. 10. The highest damage as a result of ASR was found in the multimineral coarse aggregates. These aggregates included minerals which consisted of potassium and sodium, like albite or K-feldspar, Fig. 8. In the specimens with amphibolite aggregate (A), 
granite $(\mathrm{G})$ and aggregate from glacial deposits (Gr) the significant signs of ASR were present. Owsiak et al. [15] showed that the most reactive gravel components in their research was glauconite sandstone with clay-limestone binder and chalcedony. The SEM-EDX analysis revealed that the cracks in above aggregates were filled by Si-Ca-K-Na gel, Fig. 8 . The cracks in an aggregates started in the center of grains and the sodium from deicer would start the reaction at the grain boundary. It is in agreement with earlier assumptions made by Bérubé et al. [16], that ASR damage in thin structures is reduced by leaching. In thick structures, the effect of $\mathrm{NaCl}$ is limited by its penetration depth. The ASR takes place in the inner, unaffected region as usual, i.e. is not affected by the external alkalis. In this case the formation of a swelling alkali silica gel inside the concrete leads to inhomogeneous expansion which induces cracks, [16].

In all analyzed specimens the significant changes in the concrete microstructure after WD and temperature cycles and also $10 \%$ of $\mathrm{NaCl}$ solution were visible. The presence of ettringite, Friedel's salt and alkali-silica gel were observed, however with varying intensity.

Microstructural changes for concrete specimens were observed in terms of formation of Friedel's salt. The presence of Friedel's salt in the matrix resulting to the $\mathrm{NaCl}$ application is in accordance with other researchers findings, [16-19]. Sutter et al. [20] confirmed the formation of Friedel's salt in voids in analyzed concrete specimens exposed to $\mathrm{NaCl}$ solution and examined by petrographic methods. Sibbick and Page, [18] analyzed the effect of $\mathrm{NaCl}$ exposure on ASR in concrete with regard to the alkali content of the concrete and the $\mathrm{C}_{3} \mathrm{~A}$ content of the cement. They found that the ingress of $\mathrm{NaCl}$ deicer increased the $\mathrm{NaOH}$ concentration of the pore solution owing to the reaction of chloride with the $\mathrm{C}_{3} \mathrm{~A}$ hydration products and portlandite.

Bérubé et al. [16], showed that the high sodium concentration in the near-surface layer of the concrete might not cause severe ASR owing to a decreased $\mathrm{OH}^{-}$concentration in this area. Heising et al. [17] stated that the chloride binding on hydrated cement phases and the corresponding release of $\mathrm{OH}^{-}$ions does not significantly promote ASR. The $\mathrm{OH}^{-}$ concentration, and therefore $\mathrm{pH}$, of the concrete pore solution is mainly lowered by potassium leaching, but the $\mathrm{OH}^{-}$concentration is also lowered by the formation of Friedel's salt. Both studies [17] and [16] concerned long-term soaking of concrete specimens in $\mathrm{NaCl}$ solutions at various concentrations. The effect of cyclic wetting and drying, which significantly affects the durability of the concrete, has not been considered. Wang et al. [6] investigated the impact of various deicing chemicals and exposure conditions on concrete materials. It was showed that sodium concentration of the $\mathrm{NaCl}$ immersed specimen in $6 \%$ solution was high in the near-surface layer of concrete (over 5000 and $7000 \mathrm{ppm}$ at 20 and $60 \mathrm{WD}$ cycles, respectively), but it dropped considerably with specimen depth. They stated that $\mathrm{NaCl}$ deicing chemical might penetrate into the concrete no more than $26 \mathrm{~mm}$ in depth.

The results from the conducted research according to the ASR are in agreement with above statements. The alkali-silica gel has been found in the central part of the analyzed beam specimens. The gel was present in the matrix and in the fine and coarse aggregate. The gel consisted of both, sodium and potassium ions. According to [17], the Si concentration in the pore solution increases in the presence of dissolved $\mathrm{NaCl}$. So the ASR damage should be intensified. Higher silicon solubility was explained by the higher total alkali concentration which increased surface silicate solubility, the formation of an aqueous complex $\mathrm{NaHSiO}_{3}{ }^{0}$ and a higher ionic strength. These effects promoted the sensitivity of silicate minerals to ASR, the formation of alkali silica gel and finally ASR damage, [17]. Authors [17] analysed only alkali reactive aggregate, therefore, they have achieved significant damage caused by ASR. 


\section{Conclusions}

The wetting and drying and elevated temperature cycles with application of $\mathrm{NaCl}$ deicer has been shown to promote ASR and to affect concrete both physically and chemically. The damage due to the alkali-silica reaction was present in all tested specimens, but in places farthest from the edge of concrete beams. The highest degradation was in concretes with amphibolite aggregate (A), granite aggregate $(\mathrm{G})$ and aggregate from glacial deposits $(\mathrm{Gr})$. These aggregates are characterized by minerals containing sodium and potassium, like albite and K-feldspar. The limestone and dolomite aggregates also showed ASR signs. The gel contained only sodium, with very small traces of potassium which may suggest the influence of the $\mathrm{NaCl}$ on the alkali-silica potential. The exact role of $\mathrm{NaCl}$ and sodium and potassium from aggregates still needs to be investigated in more detail.Physical effects were typically showed by cracking. The larger cracks, which were parralel to the surface, were present in the cover zone and were empty. The presence of these cracks is the result of wetting and drying cycles.

It can be concluded from the visual observations of concrete specimens that the most harmful physical and chemical exposure conditions were for specimens made with granite aggregate and aggregate from glacial deposits as against those made with basalt aggregate. The concretes with $(\mathrm{G})$ and $(\mathrm{Gr})$ aggregate subjected to sodium chloride revealed deterioration, including surface scaling and cracking.

The formations of Friedel's salt and cracks in the matrix were observed in all analyzed concrete specimens, thus the reaction mechanisms appear to be similar in all concretes.

The investigation was funded by National Centre of Research and Development in Poland and General Directorate for National Roads and Motorways, as a part of R\&D Project: Development of Road Innovations (RID) concerning "The alkali reactivity of domestic aggregates", 2016-2019

\section{References}

1. D.M Ramakrishna, T. Viraraghavan, Water, Air, and Soil Pollution 166(1-4), 49-63 (2005)

2. M.A. Glinicki, R. Jaskulski, M. Dąbrowski, Roads and Bridges - Drogi i Mosty 15(1), 21-43 (2016)

3. J. Jain, A. Janusz, J. Olek, D. Jóźwiak-Niedźwiedzka, Transportation Research Record: J. Transportation Res. Board 2290, 69-75 (2012)

4. X. Shi, L Fay, C. Gallaway, K. Volkening, M.M. Peterson, T. Pan, A. Creighton, C. Lawlor, S. Mumma, Y. Liu, T.A. Nguyen, Report No. CDOT-2009-01 (Colorado Department of Transportation, Denver, 2009)

5. L. Sutter, T. van Dam, K.R. Peterson, D.P. Johnston, Transportation Res. Record 1979, 60-68 (2006)

6. K. Wang, D.E. Nelson, W.A. Nixon, Cem. Concr. Comp. 28(2), 173-188 (2006)

7. M.C. Santagataa, M. Collepardi, Cem. Concr. Res. 30, 1389- 1394 (2000)

8. X. Shi, L. Fay, M.M. Peterson, Z. Yang, Mater. Struct. 43, 933-946 (2010)

9. P. Desai, Alkali silica reaction under the influence of chloride based deicers, 106 (M.Sc. Thesis, Clemson University, 2010)

10. F. Rajabipour, E. Giannini, C. Dunant, J.H. Ideker, M.D.A. Thomas, Cem. Concr. Res. 76, 130-146 (2015)

11. C. Giebson, K. Voland, H.-M. Ludwig, B. Meng, Struct. Concr. 18, 528-538 (2017)

12. C. Müller, I. Borchers, E. Eickschen, Beton 62(10), 397-404 (2012) 
13. D. Jóźwiak-Niedźwiedzka, K. Gibas, M.A. Glinicki, Roads and Bridges - Drogi i Mosty 16(3), 223-239 (2017)

14. Z. Naziemiec, E. Pabiś-Mazgaj, Roads and Bridges - Drogi i Mosty 16(3), 203-222 (2017)

15. Z. Owsiak, J. Zapała, P. Czapik, Cem. Wapno Beton 3, 49-154 (2012)

16. M.A. Bérubé, J.F. Dorion J.F. Duchesne, J.B. Fournier, D. Vézina, Cem. Concr. Res. 33, 77-84 (2003)

17. A. Heisig, L. Urbonas, R. E. Beddoe, D. Heinz, Mater. Struct. 49, 4291-4303 (2016)

18. R.G. Sibbick, C.L. Page, Magazine Concr. Res. 50(2), 147-159 (1998)

19. M. Balonis, B. Lothenbach, G. Le Saout, F.P. Glasser, Cem. .Concr. Res. 40, 1009-1022 (2010)

20. L. Sutter, K. Peterson, G. Julio-Betancourt, D. Hooton, T. van Dam, K. Smith, Report No. SD2002-01-X, 56 (2008) 